\title{
Analysis And Design Of Wireless Power Transfer System (Wireless Power Transfer)
}

\author{
Emil Siska Sinaga \\ Faculty Of Engineering, University Of North Sumatra, Jl. Dr. Mansur No. 9 Padang Bulan, Kec. Medan Baru, \\ Kota Medan 20222
}

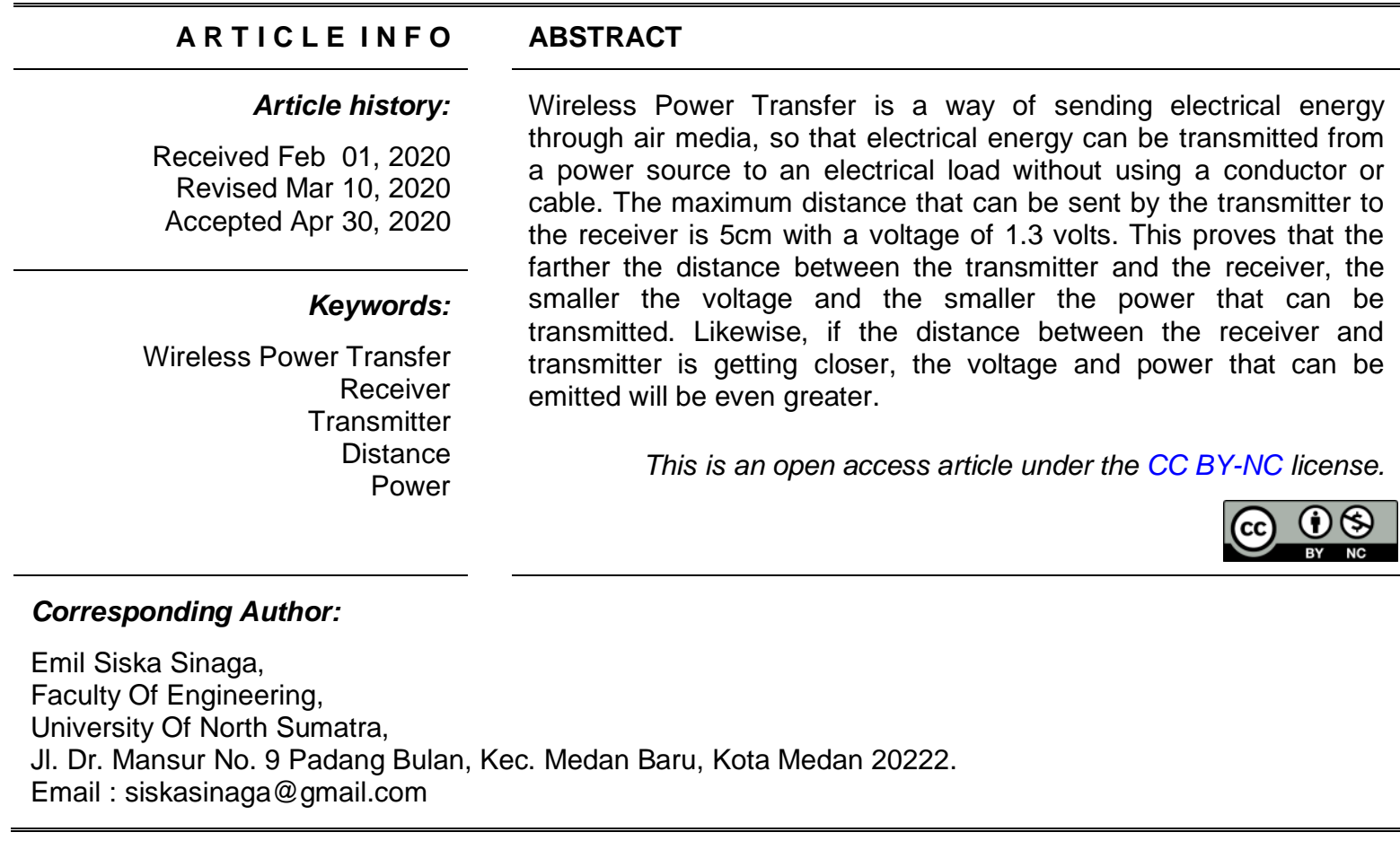

\section{INTRODUCTION}

Along with the development of technology, currently a system for transferring electrical energy without using cables has been developed. Wireless Power Transfer is one way of sending electrical energy through air media, so that electrical energy can be transmitted from a power source to a load without going through a cable. This can have an impact on the ease of power transfer and also reduce the use of cables as a power distribution medium because it is replaced by Wireless Power Transfer.

In 1899 Tesla was able to light a light bulb with a distance between the source and the load (in this case the light bulb) as far as 25 miles without using a cable media [1]. But in those days, it cost less to run a lamp 25 miles away using copper wires than it cost to build a power plant that could transmit energy wirelessly like Tesla needed. So this discovery gradually tends to be forgotten for decades.

However, research on the delivery of electrical energy without cables does not stop there. Development efforts related to this research continue to be developed by researchers around the world. Until 2007 by researchers from MIT or the Massachusetts Institute of Technology, one of whom was named Marin Soljajic, stated that the process of transferring electrical energy can be done by means of magnetic resonant coupling.

These researchers use the concept of the near field method with a close distance between the sender and the receiver. In the end, this research succeeded in transferring electrical energy 
wirelessly with a distance of more than 2 meters and the power was 60 watts, where the efficiency reached $40 \%$.

Even in subsequent research, it has been developed for the application of a Wireless Power Transfer system for transportation systems, especially railroads [3]. The results of this research later became the turning point of the development of the Wireless Power Transfer system.

\section{RESEARCH METHOD}

\subsection{Power Supply Circuit}

In this final project requires DC current for operation. The Power Supply circuit intended in this Final Project is an adapter circuit. This adapter circuit serves to convert electric current from AC current to DC current. A DC Power Supply or Adapter basically has 4 main parts in order to produce a stable DC current. The four main parts include Transformer, Rectifier, Filter and Voltage Regulator.

Power Supply used in this final project has an output voltage ranging from 1.5 volts to 15 volts with a current of $1200 \mathrm{~mA}$. The components used in the Power Supply Circuit will be described as follows. This Power Supply uses a Step Down Transformer. In the Rectifier section there are diodes that are used to rectify the waves. The filter circuit consists of a capacitor component which functions to equalize the current signal coming out of the rectifier. In the Voltage Regulator circuit, an IC is used to produce a DC voltage and current that remains stable so that the output voltage is not affected by the input voltage coming from the filter circuit output.

\subsection{Transmitter Circuit}

Transmitter circuit is a very important circuit in this final project. Because without a transmitter circuit, there will be no electromagnetic resonance process and the transmission of electrical energy without wires is impossible. The transmitter circuit works on the principle of electromagnetic resonance generated by an oscillator. The oscillator functions as a resonator that produces electromagnetic waves with a certain frequency and is emitted by induction to the receiving circuit. The way of sending power from the sender to the receiver circuit is through the sender loop, where the sender loop is a loop made of copper wire. The loop design made in this final project is a copper wire that is shaped in such a way that it forms a loop. The oscillator used in this final project is the Hartley Oscillator.

\subsection{Receiver Circuit}

The receiver circuit only consists of an inductor in the form of a coil of wire which is not much different from the coil of wire at the transmitter which is then connected to the load. Receiver circuit acts as a magnetic resonance induction catcher from the transmitter circuit to receive electrical power that will be channeled to the load. Figure 3.3 is a schematic circuit for the receiver side.

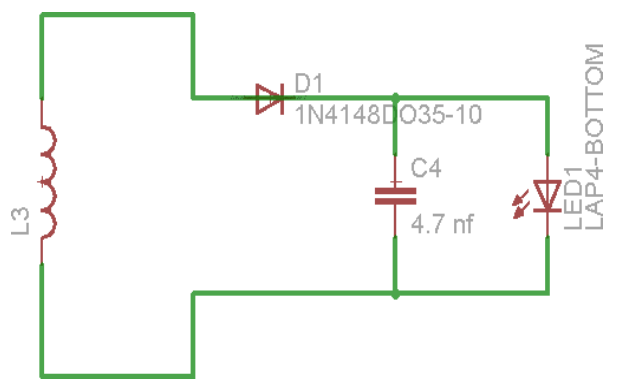

Figure 1. Receiver side schematic circuit

\subsection{Series of Wireless Power Transfer Systems}

The Power Supply circuit is a circuit that is used as a power supply circuit required by this system. The voltage source needed for this Wireless Power Transfer system is a DC voltage 
source, so an Adapter with voltage specifications that can be varied from 4 volts DC to 15 volts DC is used.

\subsection{Circuit Test Measurement Voltage and Current System Wireless Power Transfer}

Measurement of voltage and current in this wireless power transfer system uses a multimeter. In measuring the voltage, the voltmeter is placed in parallel with the circuit, while to measure the current in the circuit, the ammeter is placed in series with the circuit. The following is a picture of the experimental circuit.

\subsection{Testing the Wireless Power Transfer System using LED}

This Wireless Power Transfer System test uses LEDs as an indicator of whether or not power has been successfully sent and received by the sending and receiving sides.

\section{RESULTS AND DISCUSSIONS}

In this chapter, we will first test the tools that have been successfully made based on the designs that have been designed in the previous chapter and then discuss the data obtained from the measurement results.

This Wireless Power Transfer circuit uses a power supply in the form of a DC voltage adapter with the lowest voltage used starting from 6.5 Volts to 15 Volts. To measure the amount of energy sent, a digital multimeter is installed as a voltage and current meter on the transmitter and receiver sides. The following will describe the test data from several tests of this Wireless Power Transfer system.

\subsection{Test Data}

The test of this wireless power transfer system was carried out on 2 types of copper loops with different cross-sectional diameters. The diameter of the first copper wire is $0.3 \mathrm{~mm}$ and the diameter of the second copper wire is $0.6 \mathrm{~mm}$. For each type of copper wire diameter tested, 4 types of tests were carried out, namely by varying the input voltage, starting from 6 volts, 8 volts, 12 volts, and 15 volts. Meanwhile, for each voltage value being tested, the distance between the transmitter and receiver sides is also varied until the LED indicator lights up.

\subsection{Test Data Distance Against Voltage and Current for diameter loop 0.3mm copper.}

The first test was carried out on a coil of 30 turns, the diameter of the loop was $3.5 \mathrm{~cm}$ with a copper wire diameter of $0.3 \mathrm{~mm}$. The first process was given a source voltage of 6 volts and succeeded in transferring power at a voltage of 5.53 volts to the receiver side, as evidenced by the presence of a voltage received at the receiver side of 2.6 volts. In this condition the LED indicator on the receiver side lights up and produces a current on the LED of 0.019 amperes. Furthermore, the distance variation between the transmitter and receiver coils is carried out starting from $0.5 \mathrm{~cm}$ to $2 \mathrm{~cm}$ with a change of $0.5 \mathrm{~cm}$. The results obtained are shown in Table 1 .

Table 1. Test data with 6 volt source voltage

\begin{tabular}{cccccc}
\hline No. & Distance $(\mathrm{cm})$ & $\begin{array}{c}\text { V receiver } \\
(\text { volt })\end{array}$ & $\begin{array}{c}\text { Itransmitter } \\
(\mathrm{A})\end{array}$ & Ireceiver $^{(\mathrm{A})}$ & LED Indicator \\
\hline 1. & 0.5 & 2.6 & 0.057 & 0.019 & Life \\
2. & 1 & 2.4 & 0.051 & 0.016 & Life \\
3. & 1.5 & 2.3 & 0.045 & 0.012 & Life \\
4. & 2 & 2.08 & 0.043 & 0.007 & Dead \\
\hline
\end{tabular}

From the test data table 1 it can be seen that when the range between the transmitter and receiver sides is $0.5 \mathrm{~cm}$ to $1.5 \mathrm{~cm}$ the voltage that can be received by the receiver side is 2.6 volts and is marked by the LED indicator on the receiver side being lit. However, when the distance between the transmitter and receiver is $2 \mathrm{~cm}$, the voltage on the receiver side is only 2.08 volts, so it cannot turn on the LED indicator located on the receiver side. It can be concluded that the farther the distance between the transmitter side and the receiver side, the smaller the voltage and current and the furthest distance between the two sides allowed is $1.5 \mathrm{~cm}$. Subsequent testing with a varied 
source voltage, namely the power supply voltage of 8 Volts and a voltage of 8 volts. transferred from the transmitter side of 7.05 Volts.

Table 2. Test Data with 8 volt source voltage

\begin{tabular}{cccccc}
\hline No. & Distance $(\mathrm{cm})$ & $\begin{array}{c}\text { Vreceiver } \\
(\text { volt })\end{array}$ & Itransmitter $(\mathrm{A})$ & $\begin{array}{c}\text { Ireceiver } \\
(\mathrm{A})\end{array}$ & LED Indicator \\
\hline 1. & 0.5 & 2.8 & 0.065 & 0.031 & Life \\
2. & 1 & 2.68 & 0.060 & 0.027 & Life \\
3. & 1.5 & 2.6 & 0.056 & 0.020 & Life \\
4. & 2 & 2.4 & 0.052 & 0.013 & Life \\
5. & 2.5 & 2.08 & 0.051 & 0.008 & Dead \\
\hline
\end{tabular}

From table 2 it can be seen that the greater the voltage from the source, the greater the voltage that can be transferred. It can be seen that when the source voltage is 8 Volts, the voltage that can be transferred from the transmitter is 7.05 Volts and the furthest distance between the transmitter and receiver loops that can turn on the LED on the receiver side is $2 \mathrm{~cm}$. Unlike the previous test, which was only able to turn on the LED at a maximum distance between the transmitter and receiver of $1.5 \mathrm{~cm}$. Table 4.3 is the next test with an input voltage of 12 Volts, and a voltage that can be transferred by the sending side of 9.5 Volts.

Table 3. Test Data with input voltage of 12 volts

\begin{tabular}{|c|c|c|c|c|c|}
\hline No. & Distance $(\mathrm{cm})$ & $\begin{array}{l}V_{\text {receiver }} \\
\text { (volt) }\end{array}$ & Isend $(A)$ & $\begin{array}{l}\text { laccept } \\
\text { (A) }\end{array}$ & LED Indicator \\
\hline 1. & 0.5 & 2.9 & 0.089 & 0.052 & Life \\
\hline 2. & 1 & 2.8 & 0.084 & 0.049 & Life \\
\hline 3. & 1.5 & 2.6 & 0.081 & 0.038 & Life \\
\hline 4. & 2 & 2.4 & 0.079 & 0.026 & Life \\
\hline 5. & 2.5 & 2.1 & 0.078 & 0.016 & Dead \\
\hline
\end{tabular}

From the third test above, it can be seen that the greater the voltage given to this system, the greater the voltage that can be sent by the sending side, and the distance between the transmitter and receiver to turn on the LED will be even greater. The maximum distance between the transmitter and receiver to be able to turn on the LED is $2 \mathrm{~cm}$. Subsequent testing with a source voltage of 15 volts and a voltage that can be transferred is 11.8 volts. The following is a table of test results.

Table 4. Test Data with 15 volt source voltage

\begin{tabular}{|c|c|c|c|c|c|}
\hline No. & Distance $(\mathrm{cm})$ & $\begin{array}{c}\begin{array}{c}V_{\text {receiver }} \\
\text { (volt) }\end{array}\end{array}$ & $\begin{array}{l}\text { Isend } \\
\text { (A) }\end{array}$ & $\begin{array}{c}\text { laccept } \\
\text { (A) }\end{array}$ & LED Indicator \\
\hline 1. & 0.5 & 3.08 & 0.1194 & 0.078 & Life \\
\hline 2. & 1 & 2.9 & 0.1183 & 0.059 & Life \\
\hline 3. & 1.5 & 2.7 & 0.1177 & 0.044 & Life \\
\hline 4. & 2 & 2.5 & 0.1163 & 0.029 & Life \\
\hline 5. & 2.5 & 2.4 & 0.1147 & 0.015 & Life \\
\hline 6. & 3 & 1.94 & 0.1121 & 0.009 & Dead \\
\hline
\end{tabular}

From this last test, it is increasingly seen that the maximum distance between the transmitter and receiver that can turn on the LED is $2.5 \mathrm{~cm}$.

From the four tests carried out, it can be seen that the amount of voltage sent from the sending side greatly affects the amount of voltage that can be received by the receiving side. The distance between these two loops also greatly affects the amount of voltage that can be transmitted. The farther the distance between the transmitting loop and the receiving loop, the 
smaller the power that can be emitted by the transmitter system will be. This is due to the smaller electromagnetic field that can be captured by the receiving side. Vice versa, if the distance between the two loops is getting closer, then the electromagnetic field generated by the transmitter side will be even greater captured by the loop on the receiver side.

\subsection{Test Data Distance Against Voltage and Current for diameter loop copper $0.6 \mathrm{~mm}$.}

The following is a test carried out on the wireless power transfer system by changing the loop transmitter and loop receiver with a copper loop diameter that is larger than the previous one, which is $0.6 \mathrm{~mm}$.

Table 5. Test data loop cross-sectional area of $0.6 \mathrm{~mm}$

\begin{tabular}{|c|c|c|c|c|c|}
\hline $\begin{array}{l}\text { Source Voltage } \\
\text { (Volt) }\end{array}$ & Distance $(\mathrm{cm})$ & $\begin{array}{l}\text { V receiver } \\
\text { (volt) }\end{array}$ & $\begin{array}{l}\text { Itransmitter } \\
\text { (A) }\end{array}$ & $\begin{array}{l}\text { Ireceiver } \\
\text { (A) }\end{array}$ & LED Indicator \\
\hline \multirow[t]{3}{*}{8} & 2 & 2.6 & 0.058 & 0.019 & Life \\
\hline & 2.5 & 2.5 & 0.056 & 0.018 & Life \\
\hline & 3 & 2 & 0.043 & 0.008 & Dead \\
\hline \multirow{4}{*}{12} & 2 & 2.68 & 0.08 & 0.03 & Life \\
\hline & 2.5 & 2.60 & 0.078 & 0.026 & Life \\
\hline & 3 & 2.34 & 0.076 & 0.012 & Life \\
\hline & 3.5 & 2.02 & 0.075 & 0.004 & Dead \\
\hline \multirow{6}{*}{15} & 2 & 2.76 & 0.117 & 0.034 & Life \\
\hline & 2.5 & 2.68 & 0.116 & 0.028 & Life \\
\hline & 3 & 2.63 & 0.113 & 0.015 & Life \\
\hline & 3.5 & 2.57 & 0.112 & 0.009 & Life \\
\hline & 4 & 2.51 & 0.11 & 0.005 & Life \\
\hline & 4.5 & 2 & 0.09 & 0.001 & Dead \\
\hline
\end{tabular}

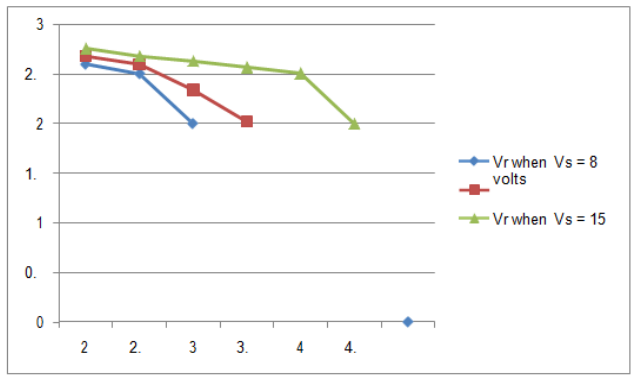

Figure 2. Graph of the Relationship between Distance and Voltage

This test shows that the greater the voltage applied to the system and the greater the crosssectional area of the copper loop, the greater the energy that can be emitted or sent to the receiving side. This is influenced by the increasing amount of magnetic flux, so that the induced emf produced will be even greater. When the input voltage is 15 volts, the maximum range between the transmitter and receiver that can turn on the LED on the receiving side is $4 \mathrm{~cm}$. Unlike when the copper loop diameter is $0.3 \mathrm{~mm}$, when the input voltage is 15 volts, the maximum range between the transmitter and receiver is only $2.5 \mathrm{~cm}$. At a distance of $4 \mathrm{~cm}$ the voltage shows 2.5 volts, and the light of the LED load is getting dimmer, the influencing factor is the farther the transmit distance between the two coils, so the electromagnetic induction will also be smaller. Unlike the case when the distance is $2 \mathrm{~cm}$, the voltage received by the receiving side is 2.7 volts, and the LED load that is installed is getting brighter, and the current is getting bigger. This proves 
that the greater the voltage, the better the transmit power. From graph 4.2 it can also be seen that the farther the distance between the two coils is, the smaller the voltage value obtained from magnetic induction will also be. So that the resulting graph form from this test is more sloping. This proves that the greater the voltage, the better the transmit power. From graph 4.2 it can also be seen that the farther the distance between the two coils is, the smaller the voltage value obtained from magnetic induction will also be. So that the resulting graph form of this test is more sloping. This proves that the greater the voltage, the better the transmit power. From graph 4.2 it can also be seen that the farther the distance between the two coils is, the smaller the voltage value obtained from magnetic induction will also be. So that the resulting graph form from this test is more sloping.

For each test in Tables 1 to 5, the power and efficiency are obtained as in Tables 6 to Tables 10. The following is a table of test data for a 6 Volt source voltage.

Table 6. Test Data with 6 volt source voltage

\begin{tabular}{llllll}
\hline No. & Distance $(\mathrm{Cm})$ & $\mathrm{P}_{\text {send }}$ & $\mathrm{P}_{\text {accept }}$ & \\
\hline 1. & 0.5 & 0.32 & 0.15 & \\
2. & 1 & & 0.28 & 0.12 & 0.47 \\
3. & \multirow{2}{*}{1.5} & 0.25 & 0.10 & 0.43 \\
4. & 2 & & 0.24 & 0.09 & 0.42 \\
\hline
\end{tabular}

From Table 6 it can be seen that if the distance between the receiver and transmitter is getting further, the power generated will also be smaller, so the efficiency is also getting smaller.

The next test is continued by measuring the amount of power sent and received by the system with a source voltage of 8 Volts.

Table 7. Test Data with 8 volt source voltage

\begin{tabular}{ccccc}
\hline No. & Distance $(\mathrm{Cm})$ & $P_{\text {send }}$ & $P_{\text {accept }}$ & $\square$ \\
\hline 1. & 0.5 & 0.46 & 0.09 & 0.19 \\
2. & 1 & 0.42 & 0.07 & 0.17 \\
3. & 1.5 & 0.39 & 0.05 & 0.13 \\
4. & 2 & 0.37 & 0.03 & 0.09 \\
5. & 2.5 & 0.36 & 0.02 & 0.05 \\
\hline
\end{tabular}

The next test calculates the sending and receiving power of the system with a 12 Volt source voltage.

Table 8. Test Data with 12 volt source voltage

\begin{tabular}{ccccc}
\hline No. & Distance $(\mathrm{Cm})$ & $\mathrm{P}_{\text {send }}$ & $\mathrm{P}_{\text {accept }}$ & $\square$ \\
\hline 1. & 0.5 & 0.85 & 0.15 & 0.18 \\
2. & 1 & 0.80 & 0.14 & 0.17 \\
3. & 1.5 & 0.77 & 0.10 & 0.13 \\
4. & 2 & 0.75 & 0.06 & 0.08 \\
5. & 2.5 & 0.74 & 0.03 & 0.05 \\
\hline
\end{tabular}

The next test is continued with a source voltage of 15 Volts to measure the sending and receiving power of the system.

Table 9. Test Data with 15 volt source voltage

\begin{tabular}{ccccc}
\hline No. & Distance $(\mathrm{Cm})$ & P $_{\text {send }}$ & $P_{\text {accept }}$ & $\square$ \\
\hline 1. & 0.5 & 1.41 & 0.24 & 0.17 \\
2. & 1 & 1.40 & 0.17 & 0.12 \\
3. & 1.5 & 1.39 & 0.12 & 0.09 \\
\hline
\end{tabular}




\begin{tabular}{lcccc}
\hline 4. & 2 & 1.37 & 0.07 & 0.05 \\
5. & 2.5 & 1.35 & 0.04 & 0.03 \\
6. & 3 & 1.32 & 0.02 & 0.01 \\
\hline
\end{tabular}

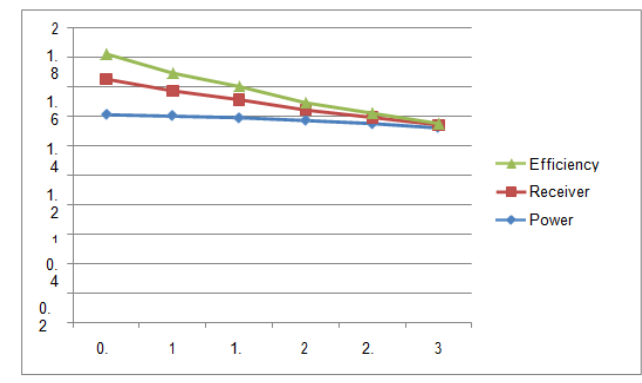

Figure 3. Comparison graph of sending power, receiving power, and efficiency when the source voltage is 15 volts.

For a copper loop cross-sectional area of $0.6 \mathrm{~mm}$, the amount of power that can be generated by the sending and receiving sides is shown in the following table 10.

Table 10. the amount of power that can be generated by the sending and receiving

\begin{tabular}{ccccc}
\hline $\begin{array}{c}\text { Voltage } \\
\text { Source (Volts) }\end{array}$ & Distance $(\mathrm{cm})$ & $P_{\text {send }}$ & Paccept & \\
\hline 8 & 2 & & & 0.12 \\
& 2.5 & 0.41 & 0.05 & 0.11 \\
& 3 & 0.39 & 0.05 & 0.05 \\
2 & 0.30 & 0.02 & 0.11 \\
12 & 2.5 & 0.76 & 0.08 & 0.09 \\
& 3 & 0.74 & 0.07 & 0.04 \\
& 3.5 & 0.72 & 0.03 & 0.01 \\
& 2 & 0.71 & 0.01 & 0.07 \\
15 & 2.5 & 1.38 & 0.09 & 0.05 \\
& 3 & 1.37 & 0.08 & 0.03 \\
& 3.5 & 1.33 & 0.04 & 0.02 \\
& 4 & 1.32 & 0.02 & 0.01 \\
\hline
\end{tabular}

\section{CONCLUSION}

Transfer of electrical energy can be done without using cables. The farther the distance between the receiver circuit and the transmitter circuit, the smaller the power that can be received by the receiver circuit. The change in the energy value sent is directly proportional to the input energy given, the greater the input energy, the greater the energy sent. The maximum power that can be generated from the transmitter circuit at a maximum adapter voltage of 15 volts at a distance of $2 \mathrm{~cm}$ is 1.38 watts with a voltage of 2.76 volts.

\section{REFERENCES}

M.Ahsan Javaid, Kamran Liaqat Bhatti, Zeeshan Raza, Umer llyas \& Shan UI Haq, "Wireless Power Transmission A Potentian Idea for Future", IJSER, 2015.

Andre Kurs,, Ariesteidis Karalis, Robert Moffatt, J.D. Joannopouos, Peter Fisher, \& Marin Soljajic, "Wireless Power Transfer Via Strongly Coupled Magnetic Resonances", Science Express, VOL.317, 2007.

Kiwon Hwang, Seonghwan Kim, Seongkyu Kim, Yangbae Chun, \& Seoungyoung Ahn, "Design Of Wireless Power Transfer System for Railway Application", IJR-International Journal of Railway, Korea, 2012.

Stanimir Valcthec, Elena Boikova, Luis Jorge, "Electromagnetic Field As The Wireless Transporter of Energy", UNINOVA PORTUGAL, UNL, Campus Caparica, Portugal, 2012.

Helmy Kautsar, "Analisa dan Rancang Bangun Rangkaian Transmitter pada Transfer Daya Listrik Tanpa Kabel", Fakultas Teknik Universitas Indonesia, 2010. 
J.William F Stevenson, "Power System Analysis", McGraw-Hill, 1984, New York.

Morris Kesler, "Highly Resonant Wireless Power Transfer : safe, efficient, and over distance", Witricity Corporation, 2013. 